\title{
Botulinum Toxin Injections in the Treatment of Blepharospasm, Hemifacial Spasm, and Eyelid Fasciculations
}

\author{
Stephen P. Kraft and Anthony E. Lang
}

\begin{abstract}
Seventy-six patients with blepharospasm (mean age 56.9 years) received 248 injection treatments with botulinum A exotoxin (mean 3.1 treatments per patient): $87.0 \%$ of treatments led to total relief of spasms for a mean interval of 14.1 weeks. The average duration of response remained fairly constant over the first six injection series, although patients with the most severe spasms had shorter intervals than patients with less severe symptoms. Twenty patients with hemifacial spasm (mean age 56.9 years) received 44 treatments (mean 1.9 treatments per patient): In $93.1 \%$ of cases there was total relief of periocular and perioral spasms, with a mean interval of 17.4 weeks. The average duration of response for the third series of treatments was much shorter than the mean durations for the first two treatments. Side effects were always transient and included ptosis $(23.3 \%)$, dry eyes (18.1\%), tearing $(5.5 \%)$, and strabismus ( $1.4 \%)$. No patient had a systemic reaction to the drug. Chronic benign eyelid fasciculations were also successfully treated in 3 patients with single treatments.
\end{abstract}

RÉSUMÉ: Traitement du blépharospasme, du spasme de l'hémiface et des fasciculations des paupières par injection de toxine botulique Soixante-seize patients atteints de blépharospasme (âge moyen 56.9 ans) ont reçu 248 traitements par injection d'exotoxine botulique A (moyenne de 3.1 traitements par patient): $87.0 \%$ des traitements ont amené une rémission totale d'une durée moyenne de 14.1 semaines. La durée de la réponse est demeurée relativement constante pendant les six premières séries d'injections, même si les patients ayant les spasmes les plus sévères ont eu des rémissions plus courtes que les patients moins atteints. Vingt patients avec spasme de l'hémiface (âge moyen 56.9 ans) ont reçu 44 traitements (moyenne de 1.9 traitements par patient). Chez $93.1 \%$ des cas, il y a eu une rémission totale des spasmes périoculaires et périoraux dont la durée moyenne était de 17.4 semaines. La durée moyenne de la réponse pour la troisième série de traitements était beaucoup plus courte que la durée moyenne pour les deux premiers traitements. Les effets secondaires ont toujours été transitoires et comprenaient la ptose (23.3\%), la xérophtalmie (18.1\%), le larmoiement $(5.5 \%)$ et le strabisme (1.4). Aucun patient n'a eu de réaction systémique au médicament. Trois patients ont également été traités avec succès par un seul traitement pour des fasciculations bénignes chroniques des paupières.

Can.J. Neurol. Sci. 1988; 15:276-280

The use of botulinum toxin in treating eye disorders was pioneered by Scott ${ }^{1}$ who introduced it as a treatment for strabismus in 1978. Botulinum toxin injections are now an accepted treatment for blepharospasm, 2-11 hemifacial spasm, ${ }^{5-12}$ and isolated eyelid disorders such as spastic entropion and benign fasciculations. ${ }^{13}$ Other dystonic movement disorders such as spasmodic torticollis, 14-16 spasmodic dysphonia, 17 oromandibular dystonia, ${ }^{18.19}$ and writer's cramp ${ }^{19.20}$ have also responded to botulinum injections.

In this study we present the results of treatment of 76 patients with blepharospasm and 20 patients with hemifacial spasm, representing one of the largest series reported for either disorder. In addition to analyzing our success rates in treating both diseases we wished to examine two other issues which have not been addressed by previous studies: 1) Does the mean duration of relief change over consecutive treatments; and 2) Does the mean duration of relief depend on the pre-injection severity of the spasms. We also report the results of treatment of 3 patients with longstanding benign eyelid fasciculations.

\section{Patients And Methods}

This report is a retrospective study of patients treated between January, 1985 and June, 1987. All patients with a diagnosis of blepharospasm (alone or as part of Meige's syndrome), hemifacial spasm, or benign eyelid fasciculations were eligible for inclusion.

Each patient had a complete ophthalmologic examination and was evaluated by at least one neurologist or neuro-ophthalmologist prior to the initial treatment. Spasms were graded on a scale of O to IV (Table 1) by one of the authors (SPK). 4,7,10,11 Prior to injection and at each followup visit the spasm severity was graded by the same author and any side effects were noted. Followup data after treatments were collected at 4 weeks after

From the Department of Ophthalmology, University of Toronto and the Movement Disorders Clinic, Toronto Western Hospital, Toronto Received January 12, 1988. Accepted April 18, 1988

Reprint requests to: Stephen P. Kraft, M.D., Hospital for Sick Children, 555 University Avenue, Toronto, Ontario, Canada M5G IX8 


$\begin{array}{ll}\text { Table 1: Grading of Spasm Intensity } \\ \text { Grade } & \text { Signs } \\ 0 & \text { No abnormality; normal blinking } \\ \text { I } & \text { Increased blink rate caused by external stimuli } \\ \text { II } & \text { Eyelid "fluttering" (tending to close; not true spasms) } \\ \text { III } & \text { Noticeable spasms; mildly incapacitating } \\ \text { IV } & \text { Severe, incapacitating spasms }\end{array}$

injection and every 2 to 3 months thereafter until the patients were reinjected. All patients included in the study had to have their latest injections by October 31, 1987 in order to define finite intervals of relief for the last injections given before June, 1987.

We considered total relief ("successful result") to be a reduction of spasms to a level of Grade 0 or I (Table 1). The interval of relief was defined as the time from treatment until the recurrence of symptoms disabling enough to force the patient to request further treatment. Thus, the interval was not taken as the interval from one treatment to the next.

The drug used in treating ocular disorders and facial spasms was a lyophilized preparation of botulinum A exotoxin. It was supplied by Scott ${ }^{\prime}$ in vials containing 140 or 200 mouse units of toxin activity. One mouse unit is equivalent to 0.4 nanograms of dried toxin. ${ }^{1,2}$ The LD50 dose for a $70 \mathrm{~kg}$ human is approximately 2.0 micrograms. ${ }^{1}$

To treat eyelid spasms the preseptal and pretarsal orbicularis muscles on each side were injected in four sites according to the protocol of Scott et al. ${ }^{2}$ For an initial treatment each site was injected with 5.0 mouse units of botulinum toxin in $0.1 \mathrm{cc}$ of non-preserved saline. In almost all patients there were concurrent eyebrow spasms, and the procerus and corrugator muscles were injected at the same time as the eyelids. ${ }^{2}$ Care was taken not to inject the central part of the upper eyelid to reduce the risk of ptosis. If a patient had no relief of spasms or a duration of effect less than 4 weeks for a given treatment, then subsequent treatments were given using doses of 10 mouse units per 0.1 cc per site. ${ }^{2}$ Any patients who had Meige's syndrome with disabling perioral spasms were offered injections of the angular oris and orbicularis oris muscles at the same time as the periocular injections were given.2,7,12 Masseters and neck muscles were not injected in this study.

Patients with hemifacial spasm had their periocular muscles and perioral muscles injected with 5.0 mouse units per site. Patients with benign eyelid fasciculations received one or two injections (5.0 or 10.0 units in total) into the orbicularis muscles in spasm. ${ }^{13}$

No patient was given a total of more than 150 mouse units (0.06 microgram) of toxin for any treatment, including those treated for Meige's syndrome.

\section{Blepharospasm and Meige's Syndrome}

A total of 76 patients were treated (Table 2). Fifty-three $(69.7 \%)$ of the patients had failed treatment with oral medications, with $19(25.0 \%)$ having tried at least three different medications. Three $(3.9 \%)$ had undergone previous facial muscle stripping 21.22 that failed, nine (11.8\%) had had blepharoplasties, and four $(5.3 \%)$ had received biofeedback or acupuncture. ${ }^{23}$

Eighteen of the patients $(23.7 \%)$ had evidence of dystonia

\begin{tabular}{|c|c|c|}
\hline & Blepharospasm & Hemifacial Spasn \\
\hline $\begin{array}{c}\text { Number of Patients } \\
\text { Female } \\
\text { Male }\end{array}$ & $\begin{array}{r}76 \\
50 \\
26\end{array}$ & $\begin{array}{r}20 \\
14 \\
6\end{array}$ \\
\hline $\begin{array}{c}\text { Mean Age (yr) at } \\
\text { Onset (Range) }\end{array}$ & $56.9(32-79)$ & $56.9(30-84)$ \\
\hline $\begin{array}{l}\text { Mean Duration (yr) of } \\
\text { Symptoms (Range) }\end{array}$ & $6.0(0.5-30)$ & $5.7(1-18)$ \\
\hline $\begin{array}{l}\text { Number Treated Previously } \\
\text { with Oral Medications } \\
1 \text { medication used } \\
2 \text { medications used } \\
3 \text { or more used }\end{array}$ & $\begin{array}{r}53 \\
25 \\
9 \\
19\end{array}$ & $\begin{array}{ll}8 & \\
& 6 \\
0 & \\
2\end{array}$ \\
\hline $\begin{array}{l}\text { Mean Age (yr) at First } \\
\text { Botulinum Treatment (Range) }\end{array}$ & $62.8(36-86)$ & $62.6(38-86)$ \\
\hline Total No. Treatments & 248 & 44 \\
\hline
\end{tabular}

elsewhere, including 10 with perioral spasms, 5 with spasmodic dysphonia, and 3 with spasmodic torticollis. Twelve patients $(15.8 \%)$ had associated neurologic disorders: 3 with Parkinson's disease, 2 with history of transient ischemic attacks, 2 with proximal myopathy, and 5 with miscellaneous diagnoses (temporal arthritis, polio, dementia, seizure disorder, and history of subdural hematoma). Seven patients $(9.2 \%)$ were receiving phenothiazines for treatment of psychiatric disorders. Other medical problems in the patient sample included hypertension (25 cases), rheumatoid arthritis (6 cases), hypothyroidism ( 5 cases), coronary artery disease ( 5 cases), diabetes ( 3 cases), Crohn's disease ( 2 cases), and colon carcinoma (2 cases).

Many patients had pre-injection ocular symptoms including $31(40.8 \%)$ who had foreign body sensations, $15(19.7 \%)$ who complained of photophobia, $12(15.8 \%)$ with red, sore eyes, and $10(13.2 \%)$ who had blurred vision (not due to cataracts or retinal diseases).

\section{Hemifacial Spasm}

A total of 20 patients were treated (Table 2). The spasms affected the left side in 13 cases $(65.0 \%)$.

Eight (40.0\%) of the patients had tried at least one medication without success. One patient failed to obtain relief with acupuncture and one had had an unsuccessful facial nerve rhizotomy. Four patients $(20.0 \%)$ had hypertension, three (15.0\%) had associated neurological disorders (transient ischemic attacks, stroke, and migraine), two (10.0\%) had coronary artery disease, one had chronic obstructive pulmonary diseasc, and one had undergone surgical excision of a colonic carcinoma.

\section{Benign Eyelid Fasciculations}

Three patients were treated for isolated unremitting lower eyelid fasciculations which had persisted between 8 and 12 months. Two were women, aged 29 and 51, and one was a man aged 58 years.

\section{RESULTS}

\section{Blepharospasm and Meige's Syndrome}

All 76 patients received treatments to the eyelids and eyebrows. 
Ten $(13.2 \%)$ had perioral spasms severe enough to require injections to facial muscles around the mouth.

The results of the three patients who had prior facial muscle surgery will be listed separately. The remaining 73 patients received a total of 240 treatments to the eyelids and brows. Patients had up to 9 treatments during the 30 -month study period (mean of 3.1 treatments per patient).

In 209 treatments $(87.0 \%)$ the best response obtained was either Grade 0 or I (Table 1). In only 7 cases was a treatment totally ineffective. In each of these seven cases a doubling of the dose per site led to reduction in symptoms of at least one grade level for the subsequent treatment.

Table 3: Duration (Weeks) of Relief After Treatments:

Blepharospasm Patients *

\begin{tabular}{clcccccc}
\hline $\begin{array}{c}\text { Pre-treatment } \\
\text { Grade }\end{array}$ & & \multicolumn{7}{c}{ Treatment } & Number & \\
\hline \multirow{2}{*}{ II } & Mean Duration & - & 16.2 & 19.5 & 16.4 & 23.0 & - \\
& Range & - & $8-24$ & $8-34$ & $10-24$ & $14-32$ & - \\
& No. Patients & 0 & 9 & 12 & 7 & 2 & 0 \\
III & Mean Duration & 15.9 & 15.3 & 18.3 & 16.8 & 14.2 & 12.7 \\
& Range & $6-60$ & $6-52$ & $7-52$ & $6-24$ & $8-32$ & $8-20$ \\
& No. Patients & 37 & 32 & 24 & 18 & 11 & 9 \\
\multirow{5}{*}{ IV } & Mean Duration & 11.9 & 12.6 & 17.3 & 9.0 & 10.9 & 12.0 \\
& Range & $4-32$ & $6-32$ & $8-32$ & $8-10$ & $6-14$ & $8-16$ \\
& No. Patients & 35 & 9 & 6 & 4 & 7 & 2 \\
OVERALL & Mean Duration & 14.0 & 14.6 & 18.5 & 15.6 & 13.9 & 11.8 \\
& Range & $4-60$ & $6-52$ & $7-52$ & $6-24$ & $6-32$ & $8-20$ \\
& No. Patients & 72 & 50 & 42 & 29 & 20 & 11 \\
\multirow{4}{*}{ No. Treatments Without Effect } & 1 & 3 & 0 & 1 & 0 & 2
\end{tabular}

* Excluding results of 3 patients who had previous facial muscle stripping.

The intervals of relief are summarized in Table 3. The grouped data are listed for only the first through sixth treatments according to pre-injection severity of spasms. There was considerable variability in duration of effect within each category of severity and treatment number, but two trends emerged in the averaged data. Firstly, for each treatment the more severe spasms the shorter was the duration of relief. This was true irrespective of the number of prior treatments. Secondly, for a given grade of pre-injection severity the durations of effect did not increase with subsequent treatments, and they actually decreased for cases with pre-injection grades III and IV.

The 3 patients who had undergone facial muscle stripping ${ }^{21,22}$ prior to their first treatments were 60,65 , and 70 years of age at the time of their initial treatments. One had no relief with the first injection and refused further botulinum injections. For the second patient the durations of relief for her two treatments were 32 and 20 weeks, and for the third patient the intervals for her five treatments were, respectively, $6,14,12,8$, and 14 weeks.

All 20 injection treatments given to the perioral muscles in the 10 patients with severe Meige's syndrome led to total relief of the lower facial spasms. The intervals of relief matched those of the orbicularis oculi injections except in two cases where the intervals for the perioral injections were four to six weeks longer.

\section{Hemifacial Spasm}

A total of 44 treatments were given to these 20 patients (mean 1.9 treatments per patient) and $41(93.1 \%)$ led to signifi- cant relief of eyelid spasms (Grade 0 or 1). No patient received more than 5 treatments during the course of this study. All 44 treatments given concurrently to the perioral muscles completely eliminated the spasms in these muscles.

The data for duration of relief for the first four treatments are presented in Table 4 . The overall average intervals for the first two treatments were longer than the comparable intervals for the blepharospasm patients. Although the number of patients who received 3 or 4 injections was small, the mean intervals were shorter for treatments 3 and 4 than for the first two treatments.

\begin{tabular}{|c|c|c|c|c|c|}
\hline \multirow{2}{*}{$\begin{array}{l}\text { Pre-treatment } \\
\text { Grade }\end{array}$} & & \multirow{2}{*}{1} & Treatment & \multicolumn{2}{|c|}{ Number } \\
\hline & & & 2 & & 4 \\
\hline \multirow[t]{3}{*}{ II } & Mean Duration & - & 26.0 & 10 & 12 \\
\hline & Range & - & $20-32$ & - & - \\
\hline & No. Patients & 0 & 2 & 1 & 1 \\
\hline \multirow{3}{*}{ III } & Mean Duration & 20.3 & 17.6 & 16.2 & 16.0 \\
\hline & Range & $10-48$ & $8-12$ & $6-15$ & $12-20$ \\
\hline & No. Patients & 13 & 9 & 5 & 2 \\
\hline \multirow[t]{3}{*}{ IV } & Mean Duration & 17.4 & 28.0 & - & - \\
\hline & Range & $10-32$ & $20-36$ & - & - \\
\hline & No. Patients & 7 & 2 & 0 & 0 \\
\hline \multirow{3}{*}{ OVERALL } & Mean Duration & 18.8 & 20.5 & 15.2 & 14.7 \\
\hline & Range & $10-48$ & $8-36$ & $6-15$ & $12-20$ \\
\hline & No. Patients & 20 & 13 & 6 & 3 \\
\hline
\end{tabular}

\section{Benign Eyelid Fasciculations}

The two women each received 10 units of toxin divided into two sites along the affected lid and the one man received a single injection of 5 units. Each patient had total relief of symptoms with no side effects. The duration of relief in these individuals thusfar have been between 60 and 80 weeks with no evidence of recurrences.

\section{Side Effects of Injections}

The local ocular side effects encountered for both the blepharospasm and hemifacial spasm patients are listed in Table 5. There were no systemic side effects seen after any treatments in either group.

The most frequent local side effect was ptosis, occurring in roughly one of every four treatments. It was temporary in all cases, with return of normal eyelid position within 8 weeks in all instances. There was no increase in frequency with dosages of 10 units compared to 5 units per site. Dry eye symptoms were less frequent and were controlled with artificial tear supplements in all but one case: This patient required punctual occlusion to prevent corneal complications. Tearing occurred after several injections but subsided in each case within 8 weeks.

Three injections for hemifacial spasm and one for blepharospasm led to vertical diplopia. The presumed mechanism is diffusion of the drug from the subcutaneous injection site through the eyelid layers to affect the superior rectus muscle. Temporary prisms were used successfully to align the images in each case. The diplopia subsided by 6 weeks after treatment in all four cases.

Among the treatments for Meige's syndrome and hemifacial spasm where perioral muscles were injected $40 \%$ led to minor 
Table 5: Ocular Side Effects of Treatments

\begin{tabular}{lcccc} 
Side Effects & $\begin{array}{c}\text { Blepharospasm Patients } \\
\text { (248 treatments) } \\
\text { Number of } \\
\text { Occurrences }\end{array}$ & Percent & $\begin{array}{c}\text { Hemifacial Spasm Patients } \\
\text { (44 treatments) } \\
\text { Number of } \\
\text { Occurrences }\end{array}$ & Percent \\
\hline Ptosis & 58 & 23.4 & 10 & 22.7 \\
$\quad$ Unilateral & 44 & 17.7 & & \\
$\quad$ Bilateral & 14 & 5.7 & 6 & 13.6 \\
Dry Eyes & 47 & 19.0 & 8 & 18.2 \\
Epiphora & 8 & 3.2 & 3 & 6.8 \\
Strabismus & 1 & 0.4 & &
\end{tabular}

difficulties with speech or chewing due to weakness of the cheek and/or angular oris muscles. Symptoms subsided in all instances within 8 weeks.

\section{Discussion}

The efficacy of botulinum toxin in relieving symptoms in patients with blepharospasm and hemifacial spasm has been noted in several studies. ${ }^{2-13}$ In addition, double blind studies have shown that botulinum toxin has a significant subjective and objective effect in relieving symptoms of facial spasms when compared with placebo. $2.18,24,25$

The dosages of botulinum toxin used for these disorders have not caused any adverse systemic effects. The LD50 dose for botulinum A exotoxin in a $70 \mathrm{~kg}$ human is estimated at 2 micrograms.1.2 The total doses used per treatment for either disorder range from 0.024 microgram (60 mouse units) to 0.60 microgram (150 units), thus allowing a large safety margin. Two studies have reported abnormal single fibre EMG recordings in muscles distant from the injection sites in patients treated for blepharospasm, but in no patient was there clinical evidence of muscle weakness. ${ }^{26.27}$

The dosages used in treating facial spasms do not stimulate a detectable antigenic response to circulating toxin. Biglan et al showed that even in patients who had 4 or 5 treatments with over 100 units per treatment no antibodies to botulinum antigen could be detected by either of two assays. ${ }^{28}$ However, the higher doses required to treat spasmodic torticollis (over 250 units per treatment) may induce antibody production with a resultant loss of clinical efficacy for subsequent treatments ( $M$. Brin, personal communication).

The incidence of side effects we encountered in treating both blepharospasm and hemifacial spasm were comparable to those in previous reports. The most frequent side effect was ptosis (approximately $25 \%$ ), and other authors have reported ranges from 10 to $50 \%, 2-8,10-13,29$ We agree with Burns et al 29 that the risk of developing ptosis after treatment for blepharospasm is not related to total dosage or to the concentration used per site. Our rate of ptosis associated with treatment of hemifacial spasm was higher than that reported by Savino et al 12 although they used concentrations of toxin ( 2.5 units per site) that were onehalf of the concentrations we used. Perhaps the drug concentration is a more significant factor in causing ptosis in cases of hemifacial spasm than it is in treating blepharospasm. The current protocol recommended by Scott et a ${ }^{2}$ avoids injection of the central part of the upper lid for treating either disorder in order to minimize the risk of ptosis.

We obtained successful results in $87 \%$ of all treatments for blepharospasm and in over $90 \%$ of treatments for hemifacial spasm. These represent substantially better results than those obtained with oral medications for either condition. ${ }^{12.30-33}$ The results for hemifacial spasm are comparable to those reported for posterior fossa decompression for this disorder with much less risk of significant complication. ${ }^{33-35}$ However, the relief obtained with injections is temporary in almost all cases, with average intervals of 3 to 4 months. Although injection treatments have to be repeated periodically for an indefinite period for both disorders, almost all of our patients willingly return for these knowing the significant relief they obtain.

In the patients treated for blepharospasm the intervals of relief were shorter the more severe the pre-injection severity of symptoms. This was not expected since the duration of action of botulinum toxin at the motor-neuron terminal should be fairly consistent. It might be explained by a retrograde effect of the toxin on brainstem receptors which may be less pronounced in the more severe forms of dystonia. Alternatively, it may simply be that more forceful contractions are able to overcome resolving lid weakness sooner than milder contractions. This phenomenon will require confirmation and further study.

We also might have expected that the denervation atrophy of muscle induced by the toxin would lead to progressively increasing duration of response with subsequent injections. This was not the case for the overall mean durations for the first 6 treatments for blepharospasm and the first 4 from hemifacial spasm. In addition, despite large variations in response intervals among patients with similar pre-injection grades, in most cases there was actually very little variation in the durations of relief for individual patients from one treatment to the next. Analysis of data from much longer term studies in the future may show a trend to longer durations of relief with greater numbers of treatments.

In summary, we have found botulinum toxin injections to be a very effective therapy for blepharospasm, hemifacial spasm, and chronic benign eyelid fasciculations. For patients with either blepharospasm or hemifacial spasm the duration of relief after treatment is temporary and consequently the treatments have to be repeated at intervals indefinitely. The duration of relief does not increase with repeated injections, and for severe cases it is shorter than for cases of moderate severity.

\section{REFERENCES}

1. Scott AB. Botulinum toxin injection of eye muscles to correct strabismus. Trans Am Ophthalmol Soc 1981: 79: 734-770.

2. Scott AB, Kennedy RA, Stubbs HA. Botulinum A toxin injection as a treatment for blepharospasm. Arch Ophthalmol 1985: 103: 347-350.

3. Elston JS, Ross Russell JW. Effect of treatment with botulinum toxin on neurogenic blepharospasm. Br Med J 1985; 290: 1857 . 1859.

4. Cohen DA, Savino PJ, Stem MB. et al. Botulinum injection therapy for blepharospasm: A review and report of 75 patients. Clin Neuropharmacol 1986; 9: 415-429.

5. Frueh BR, Felt DP, Wojno TH, et al. Treatment of blepharospasm with botulinum toxin: A preliminary report. Arch Ophthalmol 1984; 102: 1464-1468. 
6. Tsoy EA, Buckley EG, Dutton JJ. Treatment of blepharospasm with botulinum toxin. Am J Ophthalmol 1985; 99: 176-179.

7. Shorr N, Sieff SR, Kopelman J. The use of botulinum toxin in blepharospasm. Am J Ophthalmol 1985; 99: 542-546.

8. Frueh BR, Musch DC. Treatment of facial spasm with botulinum toxin: An interim report. Ophthalmology 1986; 93: 917-923.

9. Biglan AW, May M. Treatment of facial spasm with Oculinum (C. botulinum toxin). J Ped Ophthalmol Strabismus 1986; 23: 216221.

10. Perman KI, Baylis HI, Rosenbaum AL, et al. The use of botulinum toxin in the medical management of benign essential blepharospasm. Ophthalmology 1986; 93: 1-3.

11. Arthurs B, Flanders M, Codere F, et al. Treatment of blepharospasm with medication, surgery, and type A botulinum toxin. Can J Ophthalmol 1987; 22: 24-28.

12. Savino PJ, Sergott RC, Bosley TM, et al. Hemifacial spasm treated with botulinum A toxin injection. Arch Ophthalmol 1985; 103 : 1305-1306.

13. Lingua RW. Sequelae of botulinum toxin injection. Am $\mathbf{J}$ Ophthalmol 1985; 100: 305-307.

14. Tsui JK, Eisen A, Mak E, et al. A pilot study on the use of botulinum toxin in spasmodic torticollis, Can J Neurol Sci 1985; 12: 314-316.

15. Tsui, JKC. Fross RD, Calne S, et al. Local treatment of spasmodic torticollis with botulinum toxin. Can J Neurol Sci 1987; 14: 533535.

16. Greene P, Shale H, Fahn S, et al. Treatment of torticollis with injections of botulinum toxin [Abstract]. Neurology 1987; 37 (suppl 1): 123.

17. Ludlow C, Hallett M, Naunton R, et al. Treatment of spasmodic dysphonia with botulinum toxin [Abstract]. Neurology 1987; 37 (suppl 1): 124.

18. Jankovic J, Orman J. Botulinum toxin for cranial-cervical dystonia; A double-blind controlled study [Abstract]. Neurology 1986; 36 (suppl 1): 120-121.

19. Brin M, Fahn S, Moskowitz CB, et al. Injections of botulinum toxin for the treatment of focal dystonia [Abstract]. Neurology 1986; 36 (suppl I): 120.

20. Cohen L, Hallett M, Geller B, et al. Treatment of focal dystonias of the hand with botulinum toxin injection [Abstract]. Neurology 1987; 37 (suppl I): 123.
21. Gillum WN, Anderson RL. Blepharospasm surgery: An anatomic approach; Arch Ophthalmol 1981; 99: 1056-1062.

22. McCord CD Jr, Coles WH, Shore JW, et al. Treatment of essential blepharospasm. I. Comparison of facial nerve avulsion and eyebrow-eyelid muscle stripping procedure. Arch Ophthalmol 1984; 102: 266-268.

23. Surwit RS, Rotberg M. Biofeedback therapy of essential blepharospasm. Am J Ophthalmol 1984; 98: 28-31.

24. Fahn S, List T, Moskowitz C, et al. Double-blind controlled study of botulinum toxin for blepharospasm [Abstract]. Neurology 1985; 35 (suppl 1): 271.

25. Tsui JK, Eisen A, Stoessl AJ, et al. Double-blind study of botulinum toxin in spasmodic torticollis. Lancet 1986; 2: 245247.

26. Sanders DB, Massey EW, Buckley EG. Botulinum toxin for blepharospasm: Single-fibre EMG studies. Neurology 1986; 36: 545-547.

27. Lange DJ, Brin MF, Warner CL, et al. Distant effects of local injection of botulinum toxin. Muscle \& Nerve 1987; 10: 552-555.

28. Biglan AW, Gonnering R, Lockhart LB, et al. Absence of antibody production in patients treated with botulinum $A$ toxin. Am $J$ Ophthalmol 1986; 101: 232-235.

29. Burns CL, Gammon JA, Gemmill MC. Ptosis associated with botulinum toxin treatment of strabismus and blepharospasm. Ophthalmology 1986; 93: 1621-1627.

30. Marsden CD, Lang AE, Sheehy MP. The pharmacology of cranial dystonia. Neurology 1983; 33: 1100-1101.

31. Jankovic J, Ford J. Blepharospasm and oro-facial dystonia: Clinical and pharmacologic findings in 100 patients. Ann Neurol 1983; 13: 402-411.

32. Eckman PB, Kramer RA, Altrocchi PH. Hemifacial spasm. Arch Neurol 1971; 25: 81-87.

33. Jannetta PJ, Abbasy M, Maroon JC, et al: Etiology and definitive microsurgical treatment of hemifacial spasm. J Neurosurg 1977; 47: $321-328$.

34. Jannetta PJ. Hemifacial spasm: Treatment by posterior fossa surgery. J Neurol Neurosurg Psychiatry 1983; 46: 465.

35. Iwakuma T, Matsumoto A, Nakamura N. Hemifacial spasm: Comparison of three different operative procedures in 110 patients. J Neurosurg 1982; 57: 753-756. 